\title{
Relationship between hypnosis and personality trait in participants with high or low hypnotic susceptibility
}

This article was published in the following Dove Press journal:

Neuropsychiatric Disease and Treatment

3 April 2017

Number of times this article has been viewed

\author{
Yingchun Zhang ${ }^{1,2, *}$ \\ Yunke Wangl,* \\ Chanchan Shen ${ }^{1,2}$ \\ Yingying $\mathrm{Ye}^{\prime}$ \\ Si Shen' \\ Bingren Zhang ${ }^{1,2}$ \\ Jiawei Wang ${ }^{1,2}$ \\ Wei Chen ${ }^{2}$ \\ Wei Wang ${ }^{1,2}$
}

'Department of Clinical Psychology and Psychiatry, School of Public Health, ${ }^{2}$ Department of Mental Health, Sir Run Run Shaw Hospital, Zhejiang University College of Medicine, Hangzhou, People's Republic of China

*These authors contributed equally to this work
Correspondence: Wei Wang Department of Clinical Psychology and Psychiatry, School of Public Health, Zhejiang University College of Medicine, Yuhangtang Road 866, Hangzhou, Zhejiang 310058 , People's Republic of China Tel +86 57I 88208188 Email drwangwei@zju.edu.cn
Background: The relationship between normal personality and hypnotic susceptibility is important for understanding mental processing and mental disorders, but it is less consistent in normal people or in patients with a psychiatric disorder. We have hypothesized that the correlation exists but varies in individuals with different levels of hypnotizability.

Participants and methods: We invited 72 individuals with high (HIGH group) and 47 individuals with low (LOW group) hypnotic susceptibilities to undertake tests of NEO-PI-R and the Stanford Hypnotic Susceptibility Scale, Form C (SHSSC).

Results: The HIGH group scored significantly higher than the LOW group did on openness to experience and its facet openness to feelings. In the LOW group, SHSSC total was positively predicted by openness to ideas; age regression was positively predicted by openness to experience and negatively predicted by extraversion; anosmia to ammonia was negatively predicted by agreeableness; and negative visual hallucination was positively predicted by openness to experience. In the HIGH group, hallucinated voice was positively predicted by openness to experience and negatively predicted by agreeableness, and posthypnotic amnesia was positively predicted by extraversion and negatively predicted by openness to experience.

Conclusion: The associations between normal personality traits and hypnotic susceptibility items were weak and different in the two groups, which imply that managing mental or somatoform disorders might be through adjusting hypnotizability and mobilizing personality functions.

Keywords: hypnotic susceptibility, NEO-PI-R, normal personality trait, the Stanford Hypnotic Susceptibility Scale, Form C

\section{Introduction}

Hypnotic susceptibility is an ability of responsiveness to suggestions for changes in subjective experience and for alterations in perception, sensation, emotion, thought, or behavior. ${ }^{1-3}$ The ability shows hereditary inclination and remains stable during the lifetime of an individual. ${ }^{4-7}$ As a significant index reflecting the degree of hypnotic suggestions and inducement, it is purported to correlate with personality traits. In patients with a personality disorder, for example, the hypnotic features such as taste hallucination and anosmia to ammonia were correlated with the borderline personality disorder functioning style, and posthypnotic amnesia was correlated positively with the schizoid and negatively with the narcissistic styles. ${ }^{8}$

Some normal personality traits were linked with hypnotic susceptibility, but their relationships were not always stable in healthy people. ${ }^{9-11}$ The discrepancy might be resulted from various measurements of normal personality and hypnotic susceptibility. 
For instance, with the application of Intelligence Structure Test $2000 \mathrm{R}^{12}$ and the Harvard Group Scale of Hypnotic Susceptibility, Form A (HGSHSA), ${ }^{13}$ gender factor was reported as a moderator in the relationship between hypnotic susceptibility and intelligence. ${ }^{14}$

However, even with the same personality measurement, results are not consistent with each other. For example, using the Minnesota Multiphasic Personality Inventory, ${ }^{15}$ one study indicated that people with high hypnotic susceptibility scored higher in depression, masculinity-femininity, and schizophrenia scales than people with low hypnotic susceptibility did, ${ }^{16}$ but another study failed to replicate the results. ${ }^{17} \mathrm{Nev}-$ ertheless, more recent studies kept showing new evidence that persistence, ${ }^{18}$ emotional contagion, ${ }^{19}$ and unselfish/ self-sacrificing, ${ }^{20}$ were linked with hypnotic susceptibility.

In addition, using HGSHSA and the NEO Personality Inventory's openness to experience, ${ }^{21}$ Glisky et al ${ }^{22}$ have found that hypnotizability was weakly correlated with openness to experience domain and with its facets openness to fantasy, openness to esthetics, and openness to feelings. Similarly, Nordenstrom et al, ${ }^{23}$ using Carleton University Responsiveness to Suggestion Scale ${ }^{24}$ and Waterloo-Stanford Group Scale of Hypnotic Susceptibility, Form $\mathrm{C}^{25}$ in two phases, reported weak correlations between openness to experience and hypnotic suggestibility. By contrast, Green, ${ }^{26}$ using the Revised NEO Personality Inventory (NEO-PI-R), HGSHSA, and the Stanford Hypnotic Susceptibility Scale, Form C (SHSSC), ${ }^{27}$ obtained significant zero-order correlations in extraversion and agreeableness scores but failed to detect any association with openness to experience. Malinoski and Lynn ${ }^{28}$ also failed to do so with similar methods.

The inconformity of previous studies on the relationships between personality traits and hypnotic susceptibility might be due to insufficient numbers of participants, or that their participants were not highly hypnotizable. Indeed, healthy people displaying high suggestibility are grouped into a dissocial subtype with deficits in executive functioning and a predisposition to psychopathology and a subtype with superior imaginary and no observable deficits in functioning. ${ }^{29}$ Furthermore, we believe that the unclear relationship between hypnosis and personality might be resulted from using different instruments to measure the hypnotic susceptibility and personality traits, or from not administering the hypnotic measures in participants with high or low hypnotic susceptibility extremes. These earlier inconsistent results prompted us to further explore the detailed personality traits in high and low hypnotizable people. Thus, this study was designed to explore the relationships between personality traits and hypnotic susceptibility in participants with either high hypnotizability or low hypnotizability. We used the NEO-PI-R because it is an extensively used measure for normal personality traits and correlates with personality disorder functioning styles, ${ }^{30-32}$ and we used SHSSC because it is one of the widely used measures of the hypnotic susceptibility. ${ }^{33}$

\section{Participants and methods Participants}

The first three SHSSC items, ie, the hand lowering, moving hands apart, and mosquito hallucination, were used as screening for participants; those who either had passed two items (high susceptibility) or had passed only one item or failed to pass any item (low susceptibility) would be enrolled into the current study. Altogether, 340 participants from university or community were invited, but only 121 participants succeeded to be enrolled; 74 (42 women; mean age, 21.09 years with $1.63 \mathrm{SD}$; age range, 18-26 years) were classified into the low susceptibility (LOW) group, and 47 (28 women; mean age, $20.70 \pm 1.69$; age range, 18-26 years) into the high susceptibility (HIGH) group. There was no age $(F[1,119]=0.24$, $P=0.63$, mean square effect $[\mathrm{MSE}]=0.31)$ or gender $\left(\chi^{2}[1\right.$, $119]=0.094, P=0.76)$ difference between the two groups. All participants were free from somatic or psychiatric illnesses and were requested to refrain from consuming any drugs or alcohol for at least 72 hours prior to the test. The study was approved by the ethics committee of Zhejiang University College of Medicine, and all participants gave their written informed consent to participate in this study.

\section{Measures}

The participants were asked to undergo the SHSSC test and to complete the NEO-PI-R in two quiet rooms.

\section{SHSSC}

The Chinese version of the SHSSC was translated from (and back-translated to) the original English version by a professor and two PhD candidates majoring in Clinical Psychology and Psychiatry, and it has been used in a previous study. ${ }^{8}$ The SHSSC consists of 12 items including direct ideomotor (eg, arm heaviness), challenge motor (eg, arm immobilization), and cognitive-perceptual (eg, auditory hallucination) suggestions, with scores ranging from 0 to 12 . The internal alpha (reliability) of SHSSC was 0.72 in this study.

If a participant got one point on an item, we referred to this as "s/he has passed the item", otherwise as "s/he has failed to pass the item". We defined "passing rate" of each 
item as the percentage of the participants who had passed the item.

\section{NEO-PI-R}

The NEO-PI-R is a 240-item questionnaire measuring normal adult personality across the following five basic domains: neuroticism, extraversion, openness to experience, agreeableness, and conscientiousness. Six facet scales comprise each of the five domain scales and represent important constructs within each domain. The translation and psychometric properties of the Chinese language version are described elsewhere. ${ }^{34}$ The internal alphas (reliabilities) of the five scales were $0.91,0.87,0.77,0.80$, and 0.88 in this study.

\section{Statistical analyses}

Two-way analysis of variance (ANOVA) and the post hoc independent Student's $t$-test were applied to the five NEOPI-R scales in the LOW and HIGH groups. If two groups scored significantly on a domain, further analyses would be conducted on its facets. Chi-square test was used to evaluate the differences of SHSSC item passing rates in two groups. The multiple linear regression analysis (step-wise method) was used to explore the relationships between SHSSC and NEO-PI-R scales in a given group.

\section{Results}

The mean NEO-PI-R scale scores were significantly different between the two groups (group effect, $F[1,119]=10.32$, $P=0.00, \mathrm{MSE}=2,791.43$; scale effect, $F[4,116]=52.84$, $P=0.00, \mathrm{MSE}=16,716.77$; group $\times$ scale interaction effect, $F[4,116]=0.61, P=0.66$, MSE =192.06). Participants in the HIGH group scored significantly higher than those in the LOW group on openness to experience $(P=0.007,95 \%$ confidence interval $[\mathrm{CI}]=[-12.08,-1.99])$ and its facet openness to feelings $(P=0.001,95 \% \mathrm{CI}=[-3.11,-0.79])$ (Table 1$)$. The total SHSSC score was 9.49 (with $0.66 \mathrm{SD}$ ) in the HIGH group and 2.08 (1.00) in the LOW group; obviously, comparing the passing rates of SHSSC items, the HIGH group passed significantly more often than did the LOW group (Table 2).

In the LOW group, the total SHSSC score was positively predicted by openness to ideas (adjusted $R^{2}=0.157, \beta=0.086$, standard error $[\mathrm{SE}]=0.031, P=0.008,95 \% \mathrm{CI}=[0.02,0.15])$. When referring to individual SHSSC item, age regression score was positively predicted by openness to experience $(\beta=0.062$, odds ratio $[\mathrm{OR}]=1.064, \mathrm{SE}=0.024, P=0.018,95 \%$ $\mathrm{CI}=[1.02,1.12])$ and negatively predicted by extraversion $(\beta=-0.036, \mathrm{OR}=0.97, \mathrm{SE}=0.024, P=0.045,95 \% \mathrm{CI}=[0.93$,
Table I NEO-PI-R scale scores (mean \pm SD) in two groups of participants

\begin{tabular}{|c|c|c|}
\hline Scale and facet & HIGH $(n=47)$ & $\operatorname{LOW}(n=74)$ \\
\hline Neuroticism & $134.02 \pm 22.80$ & $|33.8| \pm 2 \mid .20$ \\
\hline Anxiety & $23.15 \pm 4.59$ & $23.19 \pm 5.13$ \\
\hline Angry hostility & $19.77 \pm 4.57$ & $20.59 \pm 4.60$ \\
\hline Depression & $22.09 \pm 5.57$ & $22.03 \pm 4.73$ \\
\hline Self - consciousness & $23.98 \pm 5.05$ & $23.14 \pm 4.13$ \\
\hline Impulsiveness & $24.09 \pm 4.17$ & $23.49 \pm 4.77$ \\
\hline Vulnerability & $20.96 \pm 4.94$ & $21.38 \pm 4.57$ \\
\hline Extraversion & $|58.2| \pm \mid 5.52$ & $153.55 \pm 16.86$ \\
\hline Warmth & $29.79 \pm 4.16$ & $28.78 \pm 4.82$ \\
\hline Gregariousness & $26.55 \pm 4.09$ & $26.04 \pm 4.84$ \\
\hline Assertiveness & $22.66 \pm 4.84$ & $21.55 \pm 4.50$ \\
\hline Activity & $26.38 \pm 3.92$ & $25.12 \pm 4.05$ \\
\hline Excitement seeking & $23.5 I \pm 4.44$ & $23.91 \pm 4.43$ \\
\hline Positive emotions & $29.32 \pm 4.12$ & $28.15 \pm 4.90$ \\
\hline Openness to experience & $162.02 \pm 12.90 *$ & $154.99 \pm 14.12$ \\
\hline Openness to fantasy & $25.30 \pm 4.52$ & $24.1 I \pm 4.2 I$ \\
\hline Openness to esthetics & $29.13 \pm 4.70$ & $27.38 \pm 5.34$ \\
\hline Openness to feelings & $27.83 \pm 3.01 *$ & $25.88 \pm 3.23$ \\
\hline Openness to actions & $23.43 \pm 3.01$ & $23.31 \pm 3.6 I$ \\
\hline Openness to ideas & $26.2 I \pm 4.44$ & $25.39 \pm 5.26$ \\
\hline Openness to values & $30.13 \pm 3.55$ & $28.92 \pm 3.56$ \\
\hline Agreeableness & $166.91 \pm 12.57$ & $162.65 \pm 17.56$ \\
\hline Trust & $29.43 \pm 4.51$ & $28.45 \pm 4.39$ \\
\hline Straightforwardness & $28.70 \pm 3.78$ & $27.49 \pm 4.87$ \\
\hline Altruism & $29.74 \pm 3.79$ & $29.03 \pm 4.24$ \\
\hline Compliance & $26.5 I \pm 2.84$ & $25.51 \pm 4.12$ \\
\hline Modesty & $24.06 \pm 4.30$ & $24.59 \pm 4.02$ \\
\hline Tender-mindedness & $28.47 \pm 3.35$ & $27.58 \pm 4.04$ \\
\hline Conscientiousness & $163.30 \pm 18.39$ & $157.43 \pm 19.12$ \\
\hline Competence & $26.68 \pm 3.97$ & $26.42 \pm 4.10$ \\
\hline Order & $26.34 \pm 4.12$ & $24.19 \pm 4.09$ \\
\hline Dutifulness & $31.15 \pm 3.78$ & $29.53 \pm 4.18$ \\
\hline Achievement striving & $25.91 \pm 5.06$ & $25.28 \pm 4.18$ \\
\hline Self-discipline & $27.36 \pm 4.20$ & $25.69 \pm 4.31$ \\
\hline Deliberation & $25.85 \pm 4.10$ & $26.32 \pm 4.73$ \\
\hline
\end{tabular}

Note: $* P<0.01$ vs LOW group.

Abbreviation: NEO-PI-R, Revised NEO Personality Inventory.

1.00]). Anosmia to ammonia was negatively predicted by agreeableness $(\beta=-0.074, \mathrm{OR}=0.93, \mathrm{SE}=0.036, P=0.038$, $95 \% \mathrm{CI}=[0.87,1.00])$. Negative visual hallucination score was positively predicted by openness to experience $(\beta=0.138$, $\mathrm{OR}=1.15, \mathrm{SE}=0.065, P=0.033,95 \% \mathrm{CI}=[1.01,1.30])$.

In the HIGH group, there was no association between the SHSSC total and NEO-PI-R scale scores. By contrast, the SHSSC item hallucinated voice score was positively predicted by openness to experience $(\beta=0.112, \mathrm{OR}=1.12$, $\mathrm{SE}=0.044, P=0.011,95 \% \mathrm{CI}=[1.03,1.22])$ and negatively predicted by agreeableness $(\beta=-0.086, \mathrm{OR}=0.92, \mathrm{SE}=0.037$, $P=0.021,95 \% \mathrm{CI}=[0.85,0.99])$. Posthypnotic amnesia score of SHSSC was positively predicted by extraversion $(\beta=0.008$, 
Table 2 Distribution of participants who passed the hypnotic susceptibility tests in two groups of participants

\begin{tabular}{llll}
\hline SHSSC item & \multicolumn{2}{l}{ Number, rate, \% } & \multirow{2}{*}{$\chi^{2}$} \\
\cline { 2 - 3 } & HIGH & LOW & \\
& $(\mathbf{n}=\mathbf{4 7})$ & $(\mathbf{n}=\mathbf{7 4})$ & \\
\hline Hand lowering & $46,97.9^{*}$ & $26,35.1$ & 47.0 \\
Moving hands apart & $43,91.5^{*}$ & $18,24.3$ & 51.9 \\
Mosquito hallucination & $43,91.5^{*}$ & $15,20.3$ & 58.4 \\
Taste hallucination & $44,93.6^{*}$ & $16,21.6$ & 59.6 \\
Arm rigidity & $46,97.9^{*}$ & $17,23.0$ & 64.6 \\
Dream & $31,66.0^{*}$ & $3,4.1$ & 54.5 \\
Age regression & $45,95.7^{*}$ & $39,52.7$ & 25.1 \\
Arm immobilization & $45,95.7^{*}$ & $4,5.4$ & 97.4 \\
Anosmia to ammonia & $30,63.8^{*}$ & $7,9.5$ & 40.0 \\
Hallucinated voice & $19,40.4^{*}$ & $3,4.1$ & 25.6 \\
Negative visual hallucination & $41,87.2^{*}$ & $5,6.8$ & 79.0 \\
Posthypnotic amnesia & $13,27.7^{*}$ & $1,1.4$ & 19.4 \\
\hline
\end{tabular}

Note: $* P<0.01$ vs LOW group.

Abbreviation: SHSSC, Stanford Hypnotic Susceptibility Scale, Form C.

$\mathrm{OR}=1.13, \mathrm{SE}=0.045, P=0.008,95 \% \mathrm{CI}=[1.03,1.23])$, and negatively predicted by openness to experience $(\beta=-0.138$, $\mathrm{OR}=0.87, \mathrm{SE}=0.052, P=0.008,95 \% \mathrm{CI}=[0.79,0.96])$.

\section{Discussion}

Compared to the LOW group, the HIGH group scored higher on NEO-PI-R openness to experience and its facet openness to feelings. The total SHSSC score was obviously lower in the LOW group, but it was positively associated with a trait facet openness to ideas in the group, which was roughly comparable with the previous reports. ${ }^{22,23}$ The traits agreeableness, extraversion, and openness to experience were associated with SHSSC items, but the associations were weak and their patterns were different between the two groups.

The HIGH group scored higher on openness to experience, which also accords with previous results. ${ }^{22,23}$ The trait of openness to experience covers fantasy, ${ }^{35}$ and highly suggestible individuals were fantasy-prone respondents as demonstrated previously. ${ }^{36}$ The high suggestibility enables a participant to reduce their awareness of exogenous stimuli including the auditory information, ${ }^{37}$ and the abovementioned fantasy-prone and the less filtered auditory intrusion help to explain the association between hallucinated voice and openness to experience in this group. Negative visual hallucination is similar to illusion, and hallucinations of several sensory modalities are believed to be illusions of reality in normal people. ${ }^{38}$ This notion helps to explain the association between negative visual hallucination and openness to experience found in the LOW group.

Openness to feelings implies receptivity to one's own inner feelings and emotions and the evaluation of the emotion as an important part of life. ${ }^{39}$ High hypnotic susceptibility individuals, who tend to experience more hypnotic pain or emotional disturbances, ${ }^{40,41}$ might be more sensitive and acceptable to their inner hypnotic feelings. Another study ${ }^{42}$ has demonstrated that the openness to feelings which shared a common conceptual ground with empathy, a state of unconscious emotional influence of the mind upon body, was also correlated with the hypnotizability.

It has been shown that the posthypnotic amnesia works when memory is consciously suppressed and dissociated from awareness. ${ }^{43}$ People with high openness to experience are willing to entertain novel ideas. ${ }^{39}$ The hypnotic experience seems fresh and novel for them; therefore, these people might pay more attention to the verbal or behavioral suggestions given by the experimenter during the hypnotic process. Moreover, when asked to recall the details of the experiment, highly hypnotizable people are prone to do better. These narrations in part help to explain the negative association of openness to experience with posthypnotic amnesia in the HIGH group and positive association with age regression in the LOW group. By contrast to openness to experience, extraversion was positively associated with posthypnotic amnesia in the HIGH group but negatively associated with age regression in the LOW group. Evidence has shown that the extraverts, being characterized as sociable, assertive, active, and talkative, ${ }^{39}$ are less able to focus attention on a specific task and more easily distracted by external stimuli. ${ }^{44}$ Hence extraverts incline to pay less attention to the details of the hypnotic process and cannot concentrate on the whole course of the hypnotic experiment. In contrast, hypnosis requires intensive concentration on the elaborate hypnotic suggestions, so that people would be enrolled into a hypnotic trance state. Thus, extraverts would not bear particularly detailed matters of the hypnotic experiment in mind and get higher passing rates on posthypnotic amnesia. These descriptions, also in part, help to explain why extraversion was positively associated with posthypnotic amnesia in the HIGH group and negatively associated with age regression in the LOW group. However, at present, there is no plausible explanation why openness to experience and extraversion functioned differently to the two different hypnotic aspects in different groups. Nevertheless, previous results have shown that personality disorder patients passed significantly higher on posthypnotic amnesia, and the schizoid personality disorder functioning style was positively associated with the posthypnotic amnesia and the narcissistic was negatively associated with the posthypnotic amnesia. ${ }^{8}$ Other studies have shown that the schizoid personality disorder is negatively correlated with openness to experience ${ }^{45}$ and the narcissistic is negatively correlated with extraversion. ${ }^{30}$ 
The agreeableness characterizes individuals as fundamentally altruistic, sympathetic, and helpful to others, ${ }^{39}$ and it is negatively associated with paranoid personality disorder. ${ }^{46}$ It is then easier to understand that agreeableness was negatively associated with hallucinated voice in the HIGH group. The agreeableness also ascribes individuals as amiable and peaceful to aversive situations, ${ }^{39}$ and the trait might help to elevate the threshold of ammonia provoking, thus assigning its negative association with anosmia to ammonia in the LOW group. Once more, at present, there is no plausible explanation why agreeableness was associated with two different hypnotic aspects in the two groups; however, our study demonstrated that this trait consistently helped to annihilate some hypnotic experiences.

Several limitations of the study design should also be noted. First, the age span of our participants was narrow and whether the current results can be replicated in more diverse age groups remains unclear. Second, the SHSSC items that we used for the participant screening were aimed to detect somatoform dissociation and whether they had resulted in an enrollment bias remains unknown. However, with five-factor model of normal personality, we have demonstrated that the hypnotic susceptibility was associated with openness to experience, extraversion, and agreeableness, and we have shown that these associations were weak and their patterns were different in participants with high or low hypnotizability. Moreover, our study implies that adjusting hypnotizability through mobilizing the three personality traits help to manage some mental or somatoform disorders.

\section{Conclusion}

Our results indicate that the associations between normal personality traits and hypnotic susceptibility items were weak and different in the two groups, which imply that managing mental or somatoform disorders might be through adjusting hypnotizability and mobilizing personality functions. Future studies might be designed to see the detailed correlation patterns in high and low hypnotizable people.

\section{Acknowledgment}

The study was supported by a grant from the Natural Science Foundation of China (grant no 81571336) to Dr W Wang.

\section{Disclosure}

The authors report no conflicts of interest in this work.

\section{References}

1. Hilgard ER. The domain of hypnosis: with some comments on alternative paradigms. Am Psychol. 1973;28(11):972-982.
2. Green JP, Barabasz AF, Barrett D, Montgomery GH. Forging ahead: the 2003 APA division 30 definition of hypnosis. Int J Clin Exp Hypn. 2005;53(3):259-264.

3. Silva C, Bridges KR, Metzger M. Personality, expectancy, and hypnotizability. Pers Individ Dif. 2005;39(1):131-142.

4. Morgan AH. The heritability of hypnotic susceptibility in twins. J Abnorm Psychol. 1973;82(1):55-61.

5. Lichtenberg P, Bachner-Melman R, Gritsenko I, Ebstein RP. Exploratory association between cathechol-O-methyltransferase (COMT) high/low enzyme activity polymorphism and hypnotizability. $\mathrm{Am}$ J Med Genet. 2000;96(6):771-774.

6. Morgan AH, Johnson DL, Hilgard ER. The stability of hypnotic susceptibility: a longitudinal study. Int J Clin Exp Hypn. 1974;22(3): 249-257.

7. Piccione C, Hilgard ER, Zimbardo PG. On the degree of stability of measured hypnotizability over a 25-year period. J Pers Soc Psychol. 1989;56(2):289-295.

8. Wang F, Chen W, Huang J, et al. Preliminary study of relationships between hypnotic susceptibility and personality disorder functioning styles in healthy volunteers and personality disorder patients. BMC Psychiatry. 2011;11(1):121.

9. Shor R, Orne M, O'connell D. Psychological correlates of plateau hypnotizability in a special volunteer sample. J Pers Soc Psychol. 1966; 3(1):80-95.

10. Lynn SJ, Rhue JW. The fantasy-prone person: hypnosis, imagination, and creativity. J Pers Soc Psychol. 1986;51(2):404-408.

11. Roche SM, McConkey KM. Absorption: nature, assessment, and correlates. J Pers Soc Psychol. 1990;59(1):91-101.

12. Amthauer R, Brocke B, Liepmann D, Beauducel A. Intelligenz-StrukturTest 2000 R. Göttingen: Hogrefe; 2001.

13. Shor R, Orne EC. Harvard Group Scale of Hypnotic Susceptibility, Form A. Palo Alto, CA: Consulting Psychologists; 1962.

14. Geiger E, Peter B, Prade T, Piesbergen C. Intelligence and hypnotizability: is there a connection? Int J Clin Exp Hypn. 2014;62(3):310-329.

15. Hathaway SR, Mckinley JC. Minnesota Multiphasic Personality Inventory; Manual (Revised). San Antonio, TX: Psychological Corporation; 1951.

16. Faw V, Wilcox WW. Personality characteristics of susceptible and unsusceptible hypnotic subjects. Int J Clin Exp Hypn. 1958;6:83-94.

17. Schulman RE, London P. Hypnotic susceptibilty and MMPI profiles. $J$ Consult Psychol. 1963;27:157-160.

18. Lichtenberg P, Bachner-Melman R, Ebstein RP, Crawford HJ. Hypnotic susceptibility: multidimensional relationships with Cloninger's Tridimensional Personality Questionnaire, COMT polymorphisms, absorption, and attentional characteristics. Int J Clin Exp Hypn. 2004;52(1):47-72.

19. Cardeña E, Terhune DB, Lööf A, Buratti S. Hypnotic experience is related to emotional contagion. Int J Clin Exp Hypn. 2009;57(1):33-46.

20. Peter B, Vogel SE, Prade T, Geiger E, Mohl JC, Piesbergen C. Hypnotizability, personality style, and attachment: an exploratory study, part 1 - general results. Am J Clin Hypn. 2015;57(1):13-40.

21. Costa PT, McCrae RR. The NEO Personality Inventory: Manual. Odessa, FL: Psychological Assessment Resources; 1985.

22. Glisky ML, Tataryn DJ, Tobias BA, Kihlstrom JF, McConkey KM. Absorption, openness to experience, and hypnotizability. J Pers Soc Psychol. 1991;60(2):263-272.

23. Nordenstrom BK, Council JR, Meier BP. The "big five" and hypnotic susceptibility. Int J Clin Exp Hypn. 2002;50(3):276-281.

24. Spanos NP, Radtke LH, Hodgins DC, Bertrand LD, Stam HJ, Duebreuil DL. The Carleton University Responsiveness to Suggestion Scale: stability, reliability, and relationships with expectancy and "hypnotic experiences". Psychol Rep. 1983;53:555-563.

25. Bowers KS. Waterloo-Stanford Group Scale of Hypnotic Susceptibility, Form C: manual and response booklet. Int J Clin Exp Hypn. 1998;46(3):250-268.

26. Green JP. The five factor model of personality and hypnotizability: little variance in common. Contemp Hypn. 2004;21(4):161-168. 
27. Weitzenhoffer AM, Hilgard ER. Stanford Hypnotic Susceptibility Scale, Form C. Palo Alto, CA: Consulting Psychologists Press; 1965.

28. Malinoski PT, Lynn SJ. The plasticity of early memory reports: social pressure, hypnotizability, compliance, and interrogative suggestibility. Int J Clin Exp Hypn. 1999;47(4):320-345.

29. Terhume DB, Cardeña E, Lindgren M. Dissocial tendencies and individual differences in high hypnotic suggestibility. Cogn Neuropsychiatry. 2011;16(2):113-135.

30. Wang W, Hu L, Mu L, et al. Functioning styles of personality disorders and five-factor normal personality traits: a correlation study in Chinese students. BMC Psychiatry. 2003;3(1):11.

31. Livesley WJ, Jang KL. Differentiating normal, abnormal, and disordered personality. Eur J Pers. 2005;19(4):257-268.

32. Clark LA. Assessment and diagnosis of personality disorder: perennial issues and an emerging reconceptualization. Annu Rev Psychol. 2007;58(1):227-257.

33. Champigny CM, Raz A. Transcultural factors in hypnotizability scales: limits and prospects. Am J Clin Hypn. 2015;58(2):171-194.

34. Yang J, McCrae RR, Costa PT, et al. Cross-cultural personality assessment in psychiatric populations: the NEO-PI-R in the People's Republic of China. Psychol Assess. 1999;11(3):359-368.

35. Widiger TA. The DSM-5 dimensional model of personality disorder: rationale and empirical support. J Pers Disord. 2011;25(2):222-234.

36. Cardeña E. The phenomenology of deep hypnosis: quiescent and physically active. Int J Clin Exp Hypn. 2005;53(1):37-59.

37. Okley DA, Halligan PW. Hypnotic suggestion and cognitive neuroscience. Trends Cogn Sci. 2009;13(6):264-270.
38. Bentall RP. The illusion of reality: a review and integration of psychological research on hallucinations. Psychol Bull. 1990;107(1):82-95.

39. Costa PT, McCrae RR. Revised NEO Personality Inventory (NEO-PI-R) and NEO Five Factor Inventory (NEO-FFI). Professional Manual. Odessa, FL: Psychological Assessment Resources; 1992.

40. Rogers J. Hypnosis in the treatment of social phobia. Aust J Clin Exp Hypn. 2008;36(1):64-68.

41. Huber A, Lui F, Porro CA. Hypnotic susceptibility modulates brain activity related to experimental placebo analgesia. Pain. 2013;154(9): 1509-1518.

42. Wickramasekera IE, Szlyk JP. Could empathy be a predictor of hypnotic ability? Int J Clin Exp Hypn. 2003;51(4):390-399.

43. Wagstaff GF, Parkers M, Hanley JR. A comparison of posthypnotic amnesia and the simulation of amnesia through brain injury. Rev Int Psicol Ter Psicol. 2011;1:67-78.

44. Stenburg G, Rosen I, Riseberg J. Attention and personality in augmenting/reducing of visual evoked potentials. Pers Individ Dif. 1990;11(12):1243-1254.

45. Hengartner MP, Ajdacic-Gross V, Rodgers S, Mueller M, Roessler W. The joint structure of normal and pathological personality: further evidence for a dimensional model. Compr Psychiatry. 2014;55(3): 667-674.

46. Egan V, Lewis M. Neuroticism and agreeableness differentiate emotional and narcissistic expressions of aggression. Pers Individ Dif. 2011;50(6):845-850.
Neuropsychiatric Disease and Treatment

\section{Publish your work in this journal}

Neuropsychiatric Disease and Treatment is an international, peerreviewed journal of clinical therapeutics and pharmacology focusing on concise rapid reporting of clinical or pre-clinical studies on a range of neuropsychiatric and neurological disorders. This journal is indexed on PubMed Central, the 'PsycINFO' database and CAS,

\section{Dovepress}

and is the official journal of The International Neuropsychiatric Association (INA). The manuscript management system is completely online and includes a very quick and fair peer-review system, which is all easy to use. Visit http://www.dovepress.com/testimonials.php to read real quotes from published authors. 